\title{
Política de avaliação de periódicos nas áreas de medicina: impactos sobre a produção editorial brasileira
}

\section{Luiz Roberto Curtinaz Schifini ${ }^{I}$ \\ http://orcid.org/0000-0002-3641-6986 \\ Rosângela Schwarz Rodrigues ${ }^{\text {II }}$ \\ http://orcid.org/0000-0002-9639-6390}

I Universidade Federal de Santa Catarina,Florianópolis, SC, Brasil.

Mestrando no Programa de Pós-Graduação em Ciência da Informação.

II Universidade Federal de Santa Catarina,Florianópolis, SC, Brasil.

Professora Associada no Departamento de Ciência da Informação.

http://dx.doi.org/10.1590/1981-5344/3745

Esta pesquisa analisa características dos periódicos de medicina Qualis A1 visando a construir uma reflexão crítica sobre o impacto das políticas de avaliação de periódicos na produção científica brasileira. Por meio de análise quali-quantitativa identifica características editoriais dos periódicos A1 nas áreas de Medicina I, Medicina II e Medicina III a fim de estabelecer um perfil desses periódicos. As informações foram extraídas das plataformas Sucupira, Ulrichsweb, DOAJ, Scimago Journal Rank e Journal Citation Reports. Os resultados para o perfil dos periódicos foram homogêneos entre as três áreas de medicina, e demonstraram que: são editorados majoritariamente por entidades comerciais com predominância da editora Elsevier; que a mediana do fator unificado (Fator de Impacto ou Cites per Doc) é 5,365; que a periodicidade mais observada foi a mensal; que possuem em torno de 45 anos de existência; que $13 \%$ são de Acesso Aberto; que o país predominante é os Estados Unidos e que o idioma inglês é quase unanimidade. Conclui que as características editoriais 
observadas refletem a hegemonia de conglomerados comerciais no mercado da publicação científica, e que os periódicos brasileiros, majoritariamente de Acesso Aberto e financiados com recursos públicos, não possuem condições de competir com os títulos dessas empresas.

Palavras-chave: Comunicação científica. Periódicos científicos. Qualis. Fator de impacto.

\section{Journals evaluation policy in the medical fields: impacts on brazilian editorial production}

This research analyzes the characteristics of Qualis A1 medical journals in order to set up a critical reflection on the impact of journal evaluation policies on Brazilian scientific production. Identifies editorial characteristics of the A1 journals in the areas of Medicina I, Medicina II and Medicina III through a qualitative-quantitative analysis, in order to draw a profile of these journals. The information was extracted from the following systems: Sucupira, Ulrichsweb, DOAJ, Scimago Journal Rank and Journal Citation Reports. The results for the profile of the journals were homogeneous among the three medical areas, and demonstrated that they are mainly published by commercial entities with the predominance of the publisher Elsevier; the median of the unified factor (Journal Impact Factor or Cites per Doc) is 5,365; the frequency of publishing is monthly; they are 45 years old; $13 \%$ are Open Access; the predominant country is the United States and that the English language is almost unanimous. It concludes that the observed editorial characteristics reflect the hegemony of commercial conglomerates in the academic publishing market, and that the Brazilian journals, mostly of Open Access and financed by public resources, are unable to compete with the journals of these companies. 
Keywords: Scholarly publishing. Scholarly journals.

Qualis. Journal Impact Factor.

Recebido em 09.11.2018 Aceito em 06.12.2019

\section{Introdução}

As publicações científicas veiculadas pelos periódicos funcionam como canal para o diálogo entre pesquisadores em todo o mundo, e passaram a ser parâmetro de qualidade tanto para quem as publica quanto para as instituições responsáveis pela gestão e editoração dos veículos de comunicação. Segundo Mueller (2006), os periódicos revisados por pares e indexados estão no centro do sistema tradicional de comunicação na ciência, porém esse sistema ainda enfrenta desafios quanto aos custos de assinatura e à dificuldade de acesso pelos leitores.

Em 1942 Robert Merton propôs quatro princípios que deveriam reger as ações dos cientistas perante a sociedade. São conhecidos como universalismo, comunismo, desinteresse e ceticismo. Destes, dois são destacados para a discussão deste trabalho: o comunismo - ou 'comunalismo' em traduções que procuram desambiguar do conceito marxista - afirma que os resultados da pesquisa científica devem ser de propriedade comum de toda a sociedade; e o desinteresse, que salienta a necessidade de os cientistas preterirem interesses financeiros para que possam trabalhar em prol do coletivo (MACFARLANE; MING CHENG, 2008).

No decorrer da história, desde a popularização da imprensa de Gutenberg, passando pela publicação dos primeiros periódicos e o fim da II Guerra Mundial, observa-se emergir um complexo mercado focado na editoração, na divulgação e nos direitos sobre o material científico publicado. Um mercado que movimenta bilhões de dólares negociando resultados de trabalhos de pesquisa enquanto faz o intermédio entre os pesquisadores produtores de conteúdo e outros pesquisadores leitores (BURANYI, 2017).

Atualmente, grandes conglomerados editoriais como Elsevier, Springer e Wiley dominam o nicho da comunicação científica mundial, faturando milhões de dólares em assinaturas (TENNANT, 2018). O modelo de subscrição continua dominante no mercado de publicações científicas, e apesar de material em Acesso Aberto também poder ser publicado, sua aceitação ainda não se popularizou de forma universal (ALLAHAR, 2017). Segundo levantamento do The Authorea Team (2016), os artigos mais citados na ciência são pagos e permanecem em poder de editoras 
comerciais. O levantamento realizado pela entidade apontou que 65 dos 100 artigos mais citados não podem ser lidos sem o pagamento de alguma taxa. Ou seja, as pesquisas mais referenciadas na comunidade científica estão inacessíveis para a maior parte do mundo.

Quando se trata de Acesso Aberto, o Brasil ostenta posto de grande incentivador por meio de suas universidades ou associações científicas, que assumem papéis de editoras (PACKER, 2014). No entanto o sistema Qualis, utilizado para avaliar a produção científica, ainda é alvo de críticas por se apoiar em indicadores métricos proprietários na avaliação da qualidade de periódicos, como é o caso do Fator de Impacto (FI) divulgado pelo Journal Citation Reports (JCR). O estrato Qualis exerce forte influência sobre o prestígio de um periódico científico no Brasil, o que acaba impactando em seu índice de submissões e, consequentemente, na qualidade do material publicado (COSTA; YAMAMOTO, 2008). Além disso - Qualis funciona criando demarcações entre as áreas, guiando os cientistas, influenciando no acúmulo de capital acadêmico e na alocação de recursos para financiamento de pesquisa (LEITE; CODATO, 2013).

Os periódicos brasileiros ocupam o $8^{\circ}$ lugar no ranking de produção de artigos, mas o país fica com os últimos lugares se tomado como base o Source Normalized Impact per Paper e o Journal Citation Reports (JCR). Um possível reflexo das políticas nacionais de avaliação, que favorecem a publicação em periódicos de alto impacto e, portanto, estrangeiros (PACKER; MENEGHINI, 2017). O processo de indução de alguns periódicos brasileiros, que elevou artificialmente o estrato dos títulos considerados de maior relevância, ajudou a angariar recursos e atenuou os problemas de evasão científica causados pelo Qualis; porém, segundo Kellner (2017), não foi suficiente para estimular a competitividade com os periódicos estrangeiros de alto impacto.

As áreas de medicina do Qualis são exemplos da utilização estrita de critérios baseados em indicadores de citação para classificação em estratos mais elevados. Por esse motivo optou-se por realizar um levantamento das características editoriais desses periódicos. estudar os títulos do Qualis também justifica-se pelo fato de o sistema de avaliação exercer forte influência sobre o prestígio de um periódico científico no Brasil, o que acaba impactando em seu índice de submissões e, consequentemente, na qualidade do material publicado (CABRAL FILHO, 2010; COSTA; YAMAMOTO, 2008). Além disso, no Brasil, o Qualis funciona criando demarcações entre as áreas, guiando os cientistas, influenciando no acúmulo de capital acadêmico e na alocação de recursos para financiamento de pesquisa (LEITE; CODATO, 2013). Sendo assim, com a 
intenção de investigar que perfil de periódico integra os rankings mais altos do Qualis em medicina, definiu-se o objetivo de analisar os periódicos científicos classificados como estrato $A 1$ nessas áreas. Para tanto, são apresentados os seguintes objetivos específicos: a) identificar os periódicos de estrato A1 nas áreas Medicina I, Medicina II e Medicina III do Qualis; b) examinar as características editoriais e indicadores bibliométricos dos periódicos identificados; c) traçar o perfil dos periódicos A1 em medicina com base nas características observadas em $b$.

\section{Avaliação de periódicos científicos}

O fato de membros reconhecidos da comunidade científica darem aval de qualidade aos trabalhos publicados nas revistas, concedeu às publicações periódicas um papel de protagonismo no sistema de avaliação da ciência, pois subentendia-se que o próprio feito de publicar em periódico renomado atestava automaticamente a qualidade daquilo que fosse publicado. No entanto, para que tal estratégia seja bem sucedida, é necessária confiança nos procedimentos internos adotados pelas equipes editoriais, bem como o estabelecimento de políticas transparentes sobre as avaliações e seu rigor metodológico (VASEN; VILCHIS, 2017).

Trzesniak (2006) desdobra a avaliação de periódicos científicos em quatro dimensões básicas. A primeira é a de adequação técnico-normativa da publicação periódica - compreendido pelo autor como 'produto' -, que se baseia na verificação de conformidade com as normas adotadas, como exemplo as da Associação Brasileira de Normas Técnicas (ABNT), da Organização Internacional de Normalização (ISO), ou da Associação Americana de Psicologia (APA). A segunda dimensão é a de finalidade do produto, que indica quão bem o periódico cumpre sua função baseado em critérios como a qualificação e diversidade do corpo editorial, no respaldo científico institucional, nas políticas editoriais, etc... A terceira dimensão é a de processo de produção, que deve ser baseada em diretrizes predefinidas, a fim de medir a qualidade associada aos procedimentos editoriais empregados no periódico. A quarta e última dimensão é a de mercado, que trata da qualidade que o consumidor (ou usuário) atribui ao produto, seja por resposta direta quando questionado sobre a qualidade da revista, seja refletida passivamente por estatísticas de acesso e difusão.

Segundo Bontis e Serenko (2009) há uma série de fatores e técnicas que podem ser utilizados para estimar a qualidade de um periódico. Segundo os autores, os fatores que influenciam a percepção de qualidade pelos observadores externos são a reputação do editor-chefe e do quadro 
de avaliadores, a inclusão em índices de citação, opinião de pesquisadores de referência, bom posicionamento em listas de ranqueamento, impacto, visão dos pares, longevidade do periódico, taxas de rejeição e circulação.

Em estudo conduzido por Lee et al. (2002) foram elencados critérios que, segundo os autores, representam a qualidade de periódicos científicos sobre medicina clínica e que melhor refletiriam sua razão de existência: prover os cientistas com revisão de literatura atual e relevante. Como amostra foram avaliados 243 artigos originais publicados em periódicos da área. Os critérios adotados foram a qualificação profissional e acadêmica dos pareceristas envolvidos, citação dos estudos por outras revistas, Fator de Impacto, circulação do periódico, taxa de rejeição e presença em indexadores de referência para a área.

Levando-se em conta o alto número de periódicos, analisá-los de forma individual e exaustiva também pode ser um processo moroso a ponto de tornar-se inviável. Por esse motivo, uma solução que tem sido adotada por sistemas de avaliação como o Qualis (Brasil), CIRC (Espanha) e CRMCYT (México) é terceirizar essa tarefa às bases de dados indexadoras. Pois, por associação, se um título está indexado a uma base exigente e com altos padrões de qualidade, logo, este periódico deve ter sido considerado também de alto nível.

Nesse sentido, Mugnaini (2017) afirma que uma vez tendo o atestado de qualidade emitido por uma base de dados criteriosa, não há a necessidade de uma comissão como as do Qualis replicar a aferição de mérito. Portanto, a seleção de fontes científicas qualificadas pode ser configurada em três níveis: a) os periódicos - por meio dos pareceres emitidos por seus revisores; b) as base de dados - pelos critérios de inclusão ou exclusão do material; c) as comissões das áreas de avaliação - pelas exigências específicas, que comumente se baseiam em indicadores bibliométricos. Quanto ao uso dos indicadores, no entanto, o autor ressalta que os mais utilizados são propriedade de instituições privadas, e que os principais desafios metodológicos residem na consistência de preenchimento dos metadados que alimentam as bases e no próprio fato de determinada referência citada estar ou não indexada nesses sistemas.

De fato, os índices bibliométricos como o JCR tem sido utilizados pela maioria dos países na hora de avaliar a qualidade da produção científica, além de serem usados na avaliação de pesquisadores, universidades e dos próprios países (BUELA-CASAL, 2003). Segundo Mueller (2006, p.30),

A posição de prestígio dos cientistas e dos periódicos é mantida e sustentada por um sistema de avaliação baseado em vários 
indicadores, tais como quantidade de publicações, índices de citação e visibilidade internacional. Entre os indicadores mais utilizados, mas nem por isso isentos de muitas críticas e insatisfações, estão as citações e os diversos índices derivados de sua contagem, especialmente o fator de impacto, que é uma medida da penetração ou visibilidade.

Consoante a isso, Vasen e Vilchis (2017) afirmam que os sistemas de avaliação da produção científica, especialmente na América Latina, tendem a adotar medidas ortodoxas como as baseadas em citação, em detrimento de outros indicadores que possam apontar a qualidade das publicações.

\subsection{Qualis periódicos}

O Qualis foi implantado em 1977 como uma das medidas da Coordenação de Aperfeiçoamento de Pessoal de Nível Superior (CAPES) para avaliação de desempenho dos programas de pós-graduação, almejando avaliar e estratificar qualitativamente a produção científica do país. Ao longo de seu desenvolvimento, partiu de um modelo sigiloso o qual quantificava os artigos publicados pelos programas, até chegar ao sistema atual, que classifica em diferentes níveis os veículos de comunicação científica, publicizando e atualizando periodicamente suas diretrizes (BARATA, 2016).

O estrato Qualis é um nível indicativo de qualidade, representado do maior para o menor em: A1; A2; B1; B2; B3; B4; B5 e C. Estes indicadores são atribuídos a cada periódico de acordo com a área em que o título estiver classificado e são atualizados anualmente (CAPES, 2016a). Além disso, em sua $163^{a}$ reunião o Conselho Técnico-Científico da Educação Superior (CTC-ES) propôs o enquadramento de alguns itens na categoria de "Não Periódicos" (NPCs), que incluem conferências, anais, folhetos, magazines, entre outros veículos de divulgação (RODACKI, 2016).

No total, são 48 documentos de área elaborados pelas respectivas comissões, que visam a orientar os programas quanto aos critérios exigidos para atribuição do estrato Qualis. Essas comissões possuem autonomia para selecionar, aplicar e monitorar seus próprios critérios, ao ponto que um mesmo periódico pode apresentar duas ou mais classificações em diferentes áreas. Todavia, existe uma regra de proporcionalidade na distribuição dos estratos que deve ser respeitada independentemente da área.

A regra comum estabelecida pelo CTC-ES exige que o número de periódicos dos estratos $A 1$ somado com A2 seja menor ou igual a $25 \%$ do 
total de periódicos classificados naquela área, e ainda que o percentual de periódicos $A 1$ seja menor que $A 2$. Além disso, os percentuais de $A 1$, mais $A 2$, mais $B 1$, precisam ser menores ou iguais a 50\% (CAPES, 2016a).

Como as 48 áreas possuem características diversas, a regra comum foi instituída como um mecanismo para permitir um grau mínimo de comparação entre diferentes áreas, no entanto a quantidade total de periódicos em cada uma pode prejudicar a análise. Segundo Barata (2016, p. 22 - 23) essas regras "permitem apenas uma comparação relativa, na medida em que as mesmas proporções se aplicam a totalidades muito diversas". No mesmo sentido, Manzini (2013, p. 123) afirma que "o sistema de avaliação Qualis é fechado em si mesmo" e que a CAPES limita o número de periódicos que poderão receber o selo de excelência, reconhecido na forma do estrato $A 1$.

Os métodos de avaliação adotados pela CAPES são criticados por autores como Rocha-e-Silva (2009), Mugnaini e Población (2010), Marchlewski, Silva, e Soriano (2011). Eles apontam, entre outros fatores, dificuldade de atingir estratos mais altos em certas áreas, que o sistema não considera a heterogeneidade das áreas do conhecimento e sua capacidade intrínseca de produzir citações, além de inconsistências na forma de avaliação. Já Carvalho Neto, Willinsky e Alperin (2016) afirmam que o Qualis é claramente a fonte mais compreensiva e completa para julgar as publicações científicas brasileiras.

Costa e Yamamoto (2008) percebem a importância de sinalizar o mérito científico dos trabalhos publicados, porém têm ressalvas quanto ao método Qualis. De acordo com os autores:

As avaliações de periódicos científicos, em especial aquelas destinadas à alimentação da base de dados Qualis, tornam-se uma possibilidade para prover tal diferenciação [entre trabalhos], ao classificar os títulos segundo a sua circulação, padronização e outros aspectos, permitindo uma avaliação indireta do conteúdo e autoria neles veiculados. Contudo, a avaliação Qualis não aprecia a qualidade concreta destes produtos [...] (COSTA; YAMAMOTO, 2008, p. 22).

Apesar das opiniões diversificadas na literatura, fato é que o Qualis tem como único objetivo avaliar os programas de pós-graduação, e não possui a pretensão de ditar quais periódicos são bons e quais são ruins (BARATA, 2016), no entanto o sistema passou a ser usado em critérios alheios àqueles a que se propunha originalmente. Soma, Alves e Yanasse (2016) afirmam que as listas Qualis têm sido utilizadas para avaliações 
internas em instituições de ensino, para avaliar a produção científica de indivíduos e inclusive como critério para promoção profissional.

Compreendendo-se, portanto, que a produção científica no Brasil é financiada com recursos públicos e geralmente realizada por pesquisadores vinculados a institutos de pesquisa financiados pelo governo federal ou estaduais, é natural que as agências de fomento criem mecanismos para avaliação das publicações pelas quais permeia a ciência brasileira.

\subsection{1 Áreas de medicina}

Para os propósitos das avaliações Qualis, a CAPES divide a medicina em três categorias: Medicina I, Medicina II e Medicina III, cada qual com sua própria comissão e suas próprias diretrizes. Essas diretrizes podem ser encontradas nos documentos disponibilizados pela agência por meio da plataforma Sucupira.

O que difere as áreas de Medicina I, II e III são as especialidades médicas enfocadas. A Medicina I trabalha com programas multidisciplinares das ciências da saúde e com as especialidades clínicas em Oncologia, Cardiologia, Endocrinologia, Nefrologia, Pneumologia, Gastroenterologia e Hepatologia (CAPES, 2016d). A Medicina II, por sua vez, abrange programas com atuação em Doenças Infeciosas e Parasitárias, Patologia, Pediatria, Neurologia, Psiquiatria/Saúde Mental, Radiologia, Hematologia, Reumatologia e Alergologia (CAPES, 2016e). Já a Medicina III abarca os programas relacionados à área cirúrgica e Anestesiologia (CAPES, 2016f).

Os critérios das três áreas para a classificação de periódicos são similares. Para atingir um Qualis entre os estratos A1 e B3 são extraídos o Fator de Impacto do JCR ou o Cites per Doc (2 anos) do Scimago, sendo considerado o que for mais elevado. O restante varia de acordo com a área analisada, como observado no Quadro 1.

Quadro 1 - Critérios de classificação Qualis nas áreas de medicina

\begin{tabular}{|c|c|c|c|}
\hline Estrato / Área & Medicina I & Medicina II & Medicina III \\
\hline A1 & FI ou CPD $\geq 4,5$ & FI ou CPD $\geq 4,2$ & FI ou CPD $\geq 4,4$ \\
\hline A2 & $>3,22 \leq 4,49$ & $>2,81 \leq 4,199$ & $\geq 3,11$ \\
\hline B1 & $>2,2 \leq 3,21$ & $>1,66 \leq 2,809$ & $\geq 2,1$ \\
\hline B2 & $>1,1 \leq 2,2$ & $>1 \leq 1,659$ & $\geq 1,03$ \\
\hline B3 & $>0,5 \leq 1,09$ & $>0,3 \leq 0,999$ & $\geq 0,001$ ou PubMed \\
\hline
\end{tabular}




\begin{tabular}{|c|c|c|c|}
\hline B4 & $\begin{array}{c}<0,5 \text { ou WoS, } \\
\text { Scimago ou Scopus }\end{array}$ & $\begin{array}{c}>0,001 \text { e 0,299 ou } \\
\text { Scimago, WoS, } \\
\text { PubMed ou SciELO }\end{array}$ & SciELO \\
\hline B5 & PubMed ou SciELO & Lilacs e Latindex & Lilacs \\
\hline C & $\begin{array}{c}\text { Desacordo com } \\
\text { políticas do COPE }\end{array}$ & $\begin{array}{c}\text { Desacordo com } \\
\text { políticas do COPE }\end{array}$ & $\begin{array}{c}\text { Desacordo com } \\
\text { políticas do COPE }\end{array}$ \\
\hline
\end{tabular}

Fonte: Adaptado de CAPES (2016a; 2016b; 2016c).

Apesar de os critérios serem parecidos, os números de corte de Fator de Impacto e Cites per Doc divergem um pouco entre as áreas, conforme demonstra o Quadro 1. As bases indexadoras também são critérios de classificação, porém sua adoção varia consideravelmente de acordo com a área analisada. Estar indexado na base PubMed, por exemplo, garantiria que um periódico fosse classificado como B3 em Medicina III, mas somente como B4 em Medicina II e B5 em Medicina I. Já a base SciELO seria suficiente para um periódico nas Medicinas II e III ser considerado B4, porém na Medicina I esse título estaria em B5. Na Medicina I, para ser B4, é preciso estar na Web of Science, na Scopus ou Scimago.

Os critérios de estratificação expostos no documento de área da Medicina I se mostram por vezes confusos. O quadro com os critérios dá a entender que o periódico precisaria ser indexado em ambas as bases (WoS + Scimago + Scopus) para ser considerado B4, mas posteriormente o texto esclarece que basta estar em uma delas.

Quanto à estratificação, chama a atenção o fato de bases de dados pagas e multidisciplinares, como Web of Science e Scopus serem mais relevantes para atribuição do Qualis do que as bases especializadas de medicina, como a PubMed. Organizada pela Biblioteca Nacional de Medicina dos Estados Unidos, a PubMed é uma base de dados gratuita, amplamente utilizada por médicos e reconhecida como uma das fontes mais confiáveis sobre o assunto no mundo (FALAGAS et al., 2007).

De forma geral, ambas as áreas classificam como Qualis $C$ os periódicos científicos que não atingiram os requisitos de $\mathrm{A} 1$ a B5 e aqueles em desacordo com as diretrizes de boas práticas editoriais do Committee on Publication Ethics (COPE). O COPE atua provendo seus membros com informações sobre boas práticas editoriais e aconselhamento sobre ética nas publicações. A entidade não investiga casos individuais de desvio de conduta, mas presta aconselhamento para que seus membros levem os casos às autoridades (COPE, 2018). 
Além dos estratos Qualis, as áreas de Medicina I e III utilizam a classificação de Não Periódico Científico (NPC), que corresponde aos veículos em desacordo com a definição de periódico científico da norma ABNT NBR 6021, registros informados equivocadamente pelos programas e também aqueles que não se enquadram nos critérios de nenhum estrato. A área de Medicina II utiliza o termo Periódico Não Científico (PNC), porém com descrição similar (CAPES, 2016a; 2016b; 2016c).

\section{Procedimentos metodológicos}

Os procedimentos envolvendo coleta, análise e processamento dos dados foram representados em forma de fluxo, conforme ilustra a Figura 1. O passo-a-passo foi enumerado de 1 a 8 e detalhado em seguida.

Figura 1 - Etapas da pesquisa

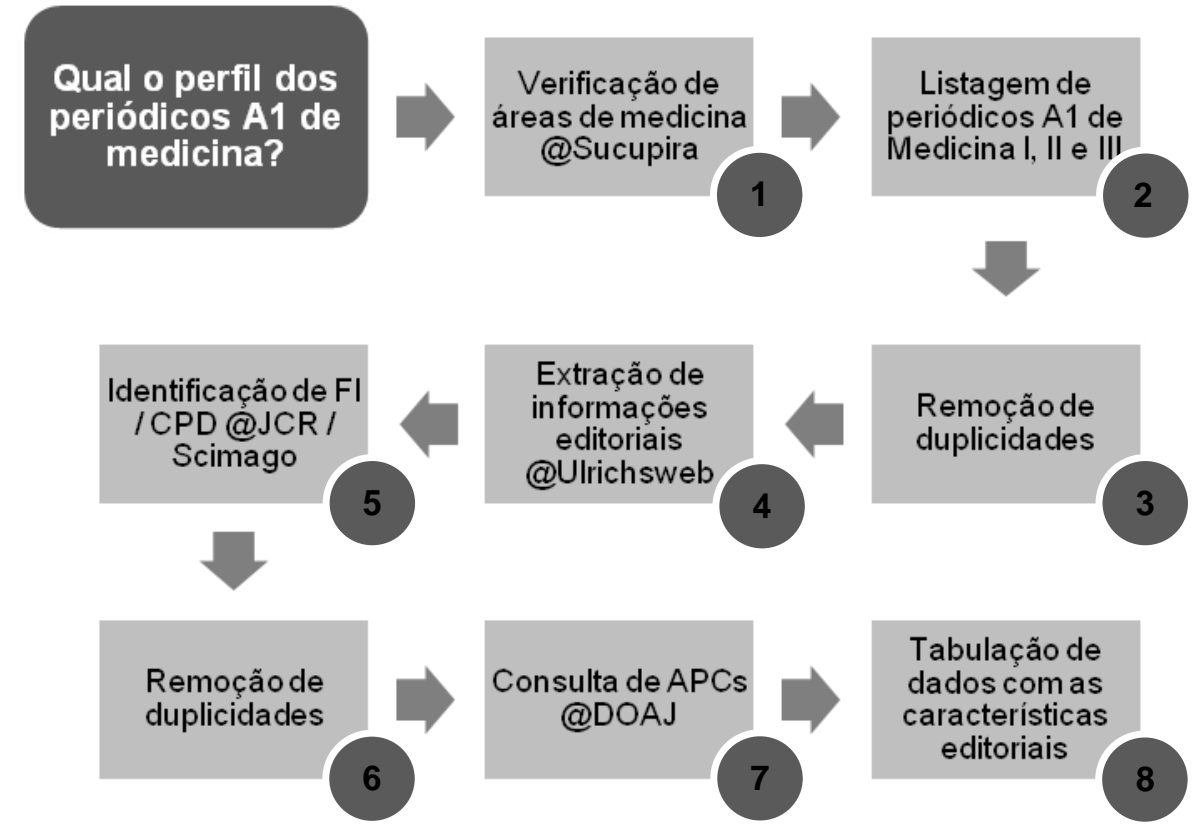

Fonte: Elaborado pelos autores.

No passo 1 foi realizada uma consulta na Plataforma Sucupira (sucupira.capes.gov.br) e selecionado o menu Qualis, em seguida o campo Qualis Periódicos. Na interface de busca foi filtrado o evento de classificação Quadriênio 2013 - 2016 e a área de avaliação Medicina I. O resultado da busca (dia 22/06/2017) gerou uma planilha com a lista de periódicos classificados na área. $O$ procedimento foi repetido nas áreas de avaliação Medicina II e Medicina III.

No passo 2 foram listados os periódicos de estrato $A 1$ contidos nas planilhas (total de 1193 itens). Esses dados foram copiados para três novas planilhas em sistema operacional tabular, separadas por área. $\mathrm{A}$ 
lista de Medicina I continha 504 itens, a lista de Medicina II continha 481 itens e a lista de Medicina III continha 208 itens.

No passo 3 foi utilizada a função do sistema para destacar números repetidos, a fim de encontrar ISSNs idênticos nas listas de Medicina I, II e III. Sete periódicos apareciam mais de uma vez na lista, sendo assim, foram eliminados. Além disso, foram verificadas as duplicidades entre áreas, pois um mesmo periódico pode ser classificado em duas ou mesmo nas três áreas de medicina.

No passo 4 foi realizada pesquisa individual por ISSN dos periódicos remanescentes via Ulrichsweb e coletadas as informações referentes a modelo de acesso, modelo de editoração (comercial ou não comercial), editora, ano de início, idioma do texto, país, periodicidade e página na internet. Os dados foram coletados entre 23/06/2017 e 15/09/2017.

No passo 5 foi consultado o Fator de Impacto de 2016 divulgado no relatório do Journal Citation Reports, além do índice Cites per Doc (2 anos) mais recente disponível no Scimago Journal Rank para todos os periódicos da lista. A consulta foi feita no período de 10/10/2017 a $03 / 04 / 2018$. Considerando que as áreas de medicina utilizam o valor mais elevado entre Fator de Impacto e Cites per Doc, nesta etapa também foi calculado um índice de citação único, sopesando o valor mais alto identificado entre os dois indicadores. Ao longo da pesquisa esse índice foi denominado fator unificado.

No passo 6 foram novamente removidas as duplicidades remanescentes por conta de ISSNs diversos. Esse procedimento foi necessário por conta de periódicos que constavam duas ou mais vezes nas listagens da Sucupira. Estavam registrados com um ISSN para impresso, outro para a versão on-line, e em alguns casos como suplementos. Para tanto, foram destacados os periódicos de Fator de Impacto ou CPD idênticos e, após conferência em seus websites, procedeu-se à eliminação daqueles que se confirmaram duplicados.

No passo 7 foram verificadas as APC dos periódicos identificados como de Acesso Aberto por meio de consulta ao DOAJ. Os valores que não estavam em dólar americano foram convertidos para essa moeda com a cotação obtida pelo website Yahoo Finance (https://finance.yahoo.com), no dia 11/05/2018. As taxas de conversão utilizadas para 1 USD foram de 0.738 GBP, 0.999 CHF e 0.837 EUR.

No passo 8 foram gerados os gráficos e quadros com as características editoriais dos periódicos A1 das medicinas, utilizando como base as informações coletadas nas etapas anteriores. Para a geração dos resultados, foram utilizadas técnicas de estatística descritiva. As médias 
dos resultados foram calculadas juntamente com suas medidas de dispersão, a fim de informar sobre a variabilidade e heterogeneidade das características dos periódicos.

\section{Resultados e discussão}

Com a análise dos periódicos das áreas Medicina I, Medicina II e Medicina III, foram coletadas informações representativas com relação ao perfil desses títulos. Os 1193 itens que constavam na lista inicial da Sucupira passaram por uma triagem para eliminar duplicidades dentro de cada área e entre as medicinas, que ao fim permitiu indentificar 528 periódicos.

Estes 528 periódicos estão distribuídos entre as três áreas de medicina, sendo que alguns deles aparecem na lista mais de uma vez pelo fato de estarem classificados em áreas diferentes. A Figura 2 ilustra a distribuição dos periódicos por área.

Figura 2 - Distribuição de periódicos por área

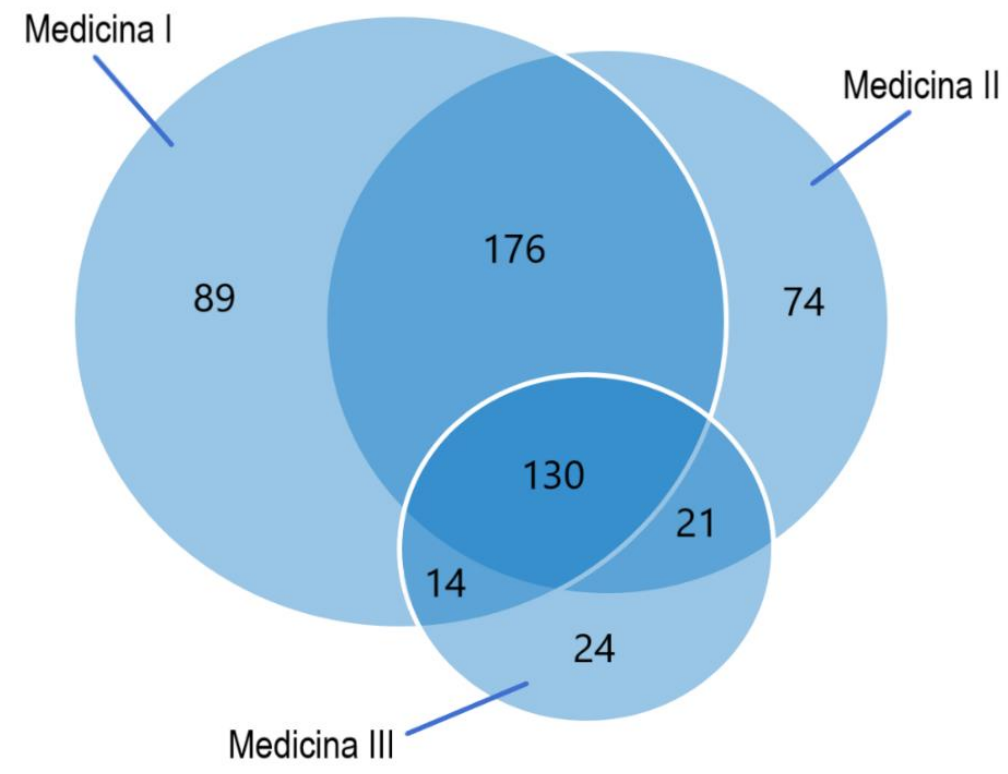

Fonte: Elaborado pelos autores.

Observa-se pela Figura 2 que a área de Medicina I é a que possui mais periódicos (409), seguida pela Medicina II (401) e pela Medicina III (189). Destes, 176 estão classificados na Medicina I e Medicina II, 14 estão na Medicina I e Medicina III, 21 na Medicina II e Medicina III e 130 estão classificados em ambas as áreas. 89 periódicos estão classificados apenas na Medicina I, 74 apenas na Medicina II e 24 apenas em Medicina III.

Foi constatada a presença de periódicos de áreas diversas às de medicina. Foram identificados periódicos das áreas de física, química, 
biologia e educação física. A constatação não surpreende, visto que o Fator de Impacto é o único critério para obtenção de Qualis A1 e a própria incidência de áreas correlatas é algo aceito pelo sistema de avaliação. Uma vez que um pesquisador vinculado a um programa de pós-graduação cadastra sua produção na plataforma Sucupira, o periódico no qual o trabalho foi publicado passa a fazer parte dos veículos classificados pelo Qualis naquela área (BARATA, 2016).

\subsection{Características dos periódicos A1 das áreas de medicina}

Não foram observadas diferenças significativas nas características editoriais entre os periódicos das Medicinas I, II e III, portanto prescindiuse de apresentar os dados separadamente por área. A fim de responder o objetivo ' $b$ ', as características editoriais são examinadas iniciando pelo fator unificado, países e idioma, periodicidade, editoras, periódicos em Acesso Aberto e ano de criação.

\subsubsection{Fator unificado dos periódicos A1 de medicina}

Fator unificado é o termo adotado pela Medicina III em seus documentos de área para indicar o maior valor entre FI e CPD, e é usado como principal critério de avaliação nas três áreas de medicina (CAPES, 2016c). Apesar de Medicina I e II não utilizarem uma nomenclatura específica, ambas consideram um único indicador para fins de avaliação. Desta forma, quando este trabalho fizer referência ao termo 'fator unificado', considera-se tratar de FI ou CPD, dependendo de qual indicador tiver apresentado maior valor. Por exemplo, se um periódico $X$ possui FI de 5,12 e CPD de 3,75, o fator unificado deste periódico será 5,12 considerando apenas o valor dado pelo FI e desprezando seu CPD.

A média do fator unificado ficou em 8,106. O maior valor observado foi de 72,406 pelo periódico The New England Journal of Medicine, e o menor foi de 0,891 pelo Alzheimer's \& Dementia: diagnosis, assessment \& disease monitoring. Segundo Bussab e Morettin (2010), os valores extremos podem prejudicar a análise feita com base na média, tendo em vista que o resultado final não representa a simetria ou assimetria da distribuição de dados, sendo pra estes casos mais adequado utilizar a medida em quartis.

Os valores identificados foram de 4,564 para o quartil inferior, 5,365 para o segundo quartil (mediana) e 6,911 para o quartil superior, conforme mostra a Figura 3. 
Figura 3 - Gráfico de distribuição do fator unificado em quartis

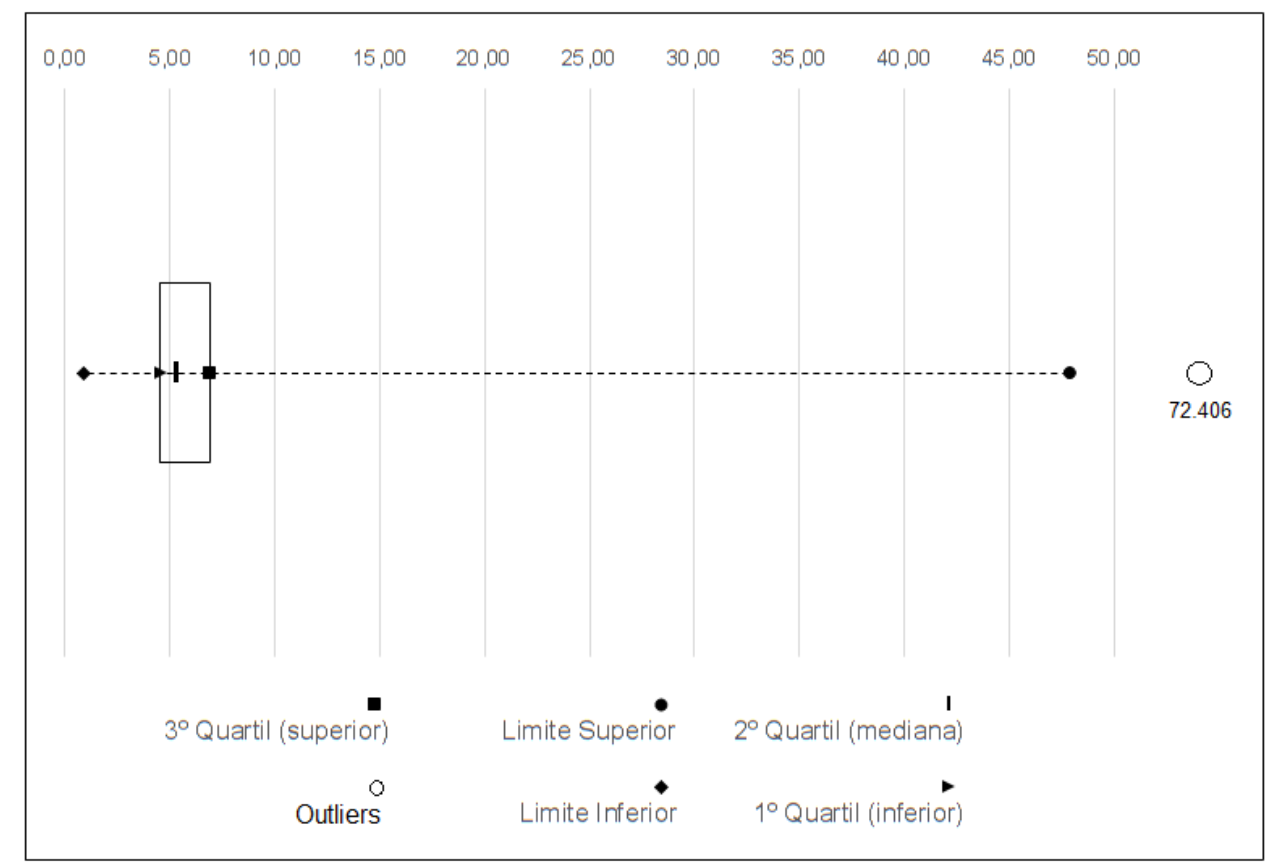

Fonte: Dados de pesquisa.

A Figura 3 é um diagrama de caixa que ilustra a dispersão dos periódicos por fator unificado. O primeiro quartil representa os $25 \%$ dos periódicos cujo fator unificado encontra-se abaixo de 4,564. O segundo quartil é a mediana, com $50 \%$ acima e outros $50 \%$ abaixo de 5,365 . A parcela do terceiro quartil mostra que $75 \%$ do total tem no máximo 6,911 de fator unificado. Percebe-se que mesmo o quartil superior apresentou valores mais baixos em relação ao obtido pela média $(8,106)$. A linha pontilhada apresenta a amplitude entre quartis, que vai de 0,891 a 47,831, com um ponto discrepante (outlier) de 72,406. É possível observar, também, que a posição da mediana não está exatamente no centro do retângulo dos quartis, o que caracteriza uma distribuição assimétrica dos valores de fator unificado.

Houve 48 casos de periódicos abaixo de 4,2 no fator unificado, 0 que os colocam abaixo dos critérios de estrato $A 1$ nas três áreas. Nas medicinas I e III, em que o corte é mais elevado, os números de periódicos abaixo dos critérios ficam em 75 e 63, respectivamente. Dos que se encontram abaixo da cota, 53 atendem no máximo os critérios para serem classificados como A2, oito como B1, dois como B2, outros dois como B5, e um como C.

A lista da CAPES não estava atualizada conforme o último FI ou CPD lançado nos relatórios do JCR ou Scimago, portanto procedeu-se à verificação de indicadores anteriores que estivessem no quadriênio de abrangência da avaliação do Qualis (2013-2016). A conclusão utilizando 
essa margem temporal foi que a maioria desses periódicos apresentou um fator unificado de acordo com os critérios exigidos para A1 em algum ano anterior, porém houve quatorze casos em que o título nunca teve FI ou CPD para estar no estrato indicado.

Em estudo anterior sobre os periódicos da Medicina III, a problemática da atualização nas avalições do Qualis com a utilização do FI já havia sido levantada. Segundo Calderon (2015, p. 66 - 67),

[...] forma-se ciclo vicioso entre FI das publicações e média e/ou mediana das subáreas e da Área Medicina III que, nem sempre é acompanhado da atualização do sistema Qualis-periódicos/Capes. Ou seja, os limites dos estratos Qualis-periódicos, por serem atualizados a partir das publicações de um determinado período (biênio, triênio ou quadriênio), poderão não representar a real qualidade das publicações no momento da avaliação, o que torna esse indicador insuficiente para o quesito produção bibliográfica.

De forma geral, as medianas de fator unificado ainda estão bem acima do que existe no cenário nacional, considerando os dados do JCR de 2017. No relatório o periódico brasileiro com maior impacto é o Journal of Materials Research and Technology, que possui FI de 3,398, classificado como Qualis A1 da área de Engenharias II. Nas áreas de medicina o maior FI pertence ao Memórias do Instituto Oswaldo Cruz, com o valor de 2,833, que também aparece ranqueado como segundo lugar geral do Brasil e possui Qualis B2 nas medicinas I, II e III.

Analisando os critérios de área expostos no Quadro 1, o FI apresentado pelo periódico Memórias do Instituto Oswaldo Cruz lhe garantiria estrato B1 nas medicinas I e III, e estrato A2 na Medicina II. O fato de o título não estar classificado em estrato compatível com seus indicadores demonstra que há uma lacuna no sistema de avaliação da CAPES, seja pela falta de atualização regular, seja pelo limitador de periódicos por estrato.

\subsubsection{Países e idioma dos periódicos A1 de medicina}

A maior parte dos periódicos identificados nesta pesquisa são provenientes dos Estados Unidos (235), seguidos por Reino Unido (202), Holanda (34) e Alemanha (21). Em termos percentuais isso equivale a $44,5 \%$ de periódicos dos Estados Unidos, 38,25\% do Reino Unido, 6,43\% da Holanda e 3,97\% da Alemanha.

Os resultados coincidem com o fato de esses quatro países serem os berços das cinco maiores editoras acadêmicas comerciais. Estados unidos contam com Wiley-Blackwell e Sage; Reino Unido com Taylor \& Francis; 
Holanda com Elsevier; Alemanha com Springer. Na outra extremidade do gráfico, ficaram Austrália, Itália, Singapura e Espanha, que apresentaram apenas um periódico cada, conforme mostra a Figura 4:

Figura 4 - Gráfico de periódicos por países

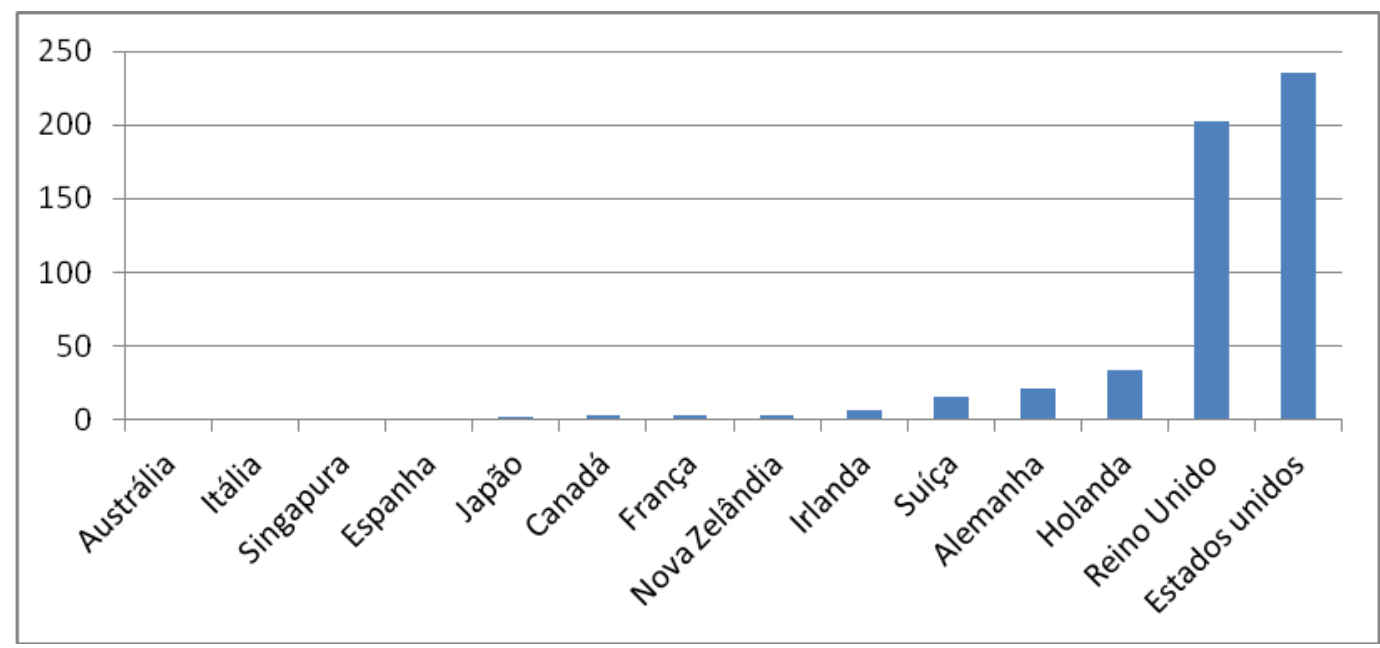

Fonte: Dados de pesquisa.

Não há periódicos nacionais nas listas de A1 das medicinas, como é possível observar pelo gráfico da Figura 4. Segundo Barbosa (2016), o próprio fato de um periódico ser oriundo dos Estados Unidos faz com que ele atraia mais a atenção de pesquisadores interessados em publicar seus trabalhos, pois os artigos desse país costumam ganhar mais destaque internacional, sendo portanto mais lidos e mais citados.

Políticas de fomento são requeridas num cenário em que a publicação em periódicos estrangeiros é privilegiada pelos critérios de avaliação do Qualis. Segundo Barbosa (2016), o próprio fato de um periódico ser oriundo dos Estados Unidos faz com que ele atraia mais a atenção de pesquisadores interessados em publicar seus trabalhos, pois os artigos desse país costumam ganhar mais destaque internacional, sendo portanto mais lidos e mais citados.

Ao verificar a citação por país, no entanto, observam-se resultados mais simétricos. Estados Unidos $(6,315)$ e Reino Unido $(6,044)$, nesse caso, são superados por Itália $(7,702)$ e Singapura $(6,333)$. A Austrália foi o país que apresentou o menor fator unificado $(4,218)$.

Quanto ao idioma dos textos publicados, são apenas dois periódicos que não publicam em inglês. Um publica em espanhol e o outro em alemão. Nove publicam em inglês juntamente com outros idiomas e os outros 517 periódicos publicam exclusivamente em inglês. Com base nessas informações é possível observar a dominância do idioma inglês nos textos das publicações. Na grande maioria dos periódicos a língua inglesa 
é a única utilizada, e mesmo nos casos em que outros idiomas são observados, o inglês aparece como secundário.

Publicar no idioma inglês é tido como critério chave para que os periódicos sejam incluídos na maioria das bases indexadoras internacionais e possam ser citados, porém não é o suficiente. Uma simples tradução em inglês não consegue competir com a produção textual de países cujo inglês é língua nativa. Nesse sentido, Mueller (1999, p.1) afirma que

Os periódicos científicos publicados pelos países que não estão na fronteira do desenvolvimento da ciência e não têm o inglês como língua nacional não têm o prestígio de um periódico de primeira linha. Mesmo que sejam incluídos nos periódicos de resumo da área em que publicam, não conseguem entrar no círculo de periódicos regularmente analisados pelos prestigiosos índices de citação.

Considerando que a análise demonstrou a presença do idioma inglês em quase que a totalidade dos periódicos analisados, e que a grande maioria deles são oriundos de Reino Unido e Estados Unidos, nos quais o inglês é língua oficial, a assertiva de Mueller (1999) mostra-se pertinente. Ainda que a internacionalização e a publicação em inglês seja estimulada por bases como a SciELO - que para os periódicos das áreas de saúde exige o mínimo de $80 \%$ de artigos neste idioma (SCIELO, 2017) - a produção dos cientistas de países periféricos dificilmente consegue atingir a mesma qualidade de redação que a dos falantes nativos ou de países desenvolvidos com mais tradição nesse tipo de comunicação.

\subsubsection{Periodicidade dos periódicos A1 de medicina}

Na definição da norma da Associação Brasileira de Normas Técnicas (2003, p.3), periodicidade é o "intervalo de tempo entre a publicação sucessiva dos fascículos de um mesmo título de publicação". Portanto, a periodicidade de uma revista vai ser definida de acordo com a quantidade e intervalo de edições publicadas em seu ano ativo. A manutenção da periodicidade regular e pontual é compreendida como aspecto de qualidade na literatura científica (KRZYZANOWSKI; FERREIRA, 1998; STUMPF, 2003; YAMAMOTO et al., 2002), além de critério de adesão em diversas bases indexadoras, como SciELO, Redalyc e Latindex.

O número de fascículos publicados por ano ficou com uma média em torno de 14 edições e a periodicidade mais recorrente foi a mensal, como mostra a figura 5 , a seguir. 
Figura 5 - Gráfico de fascículos publicados por ano

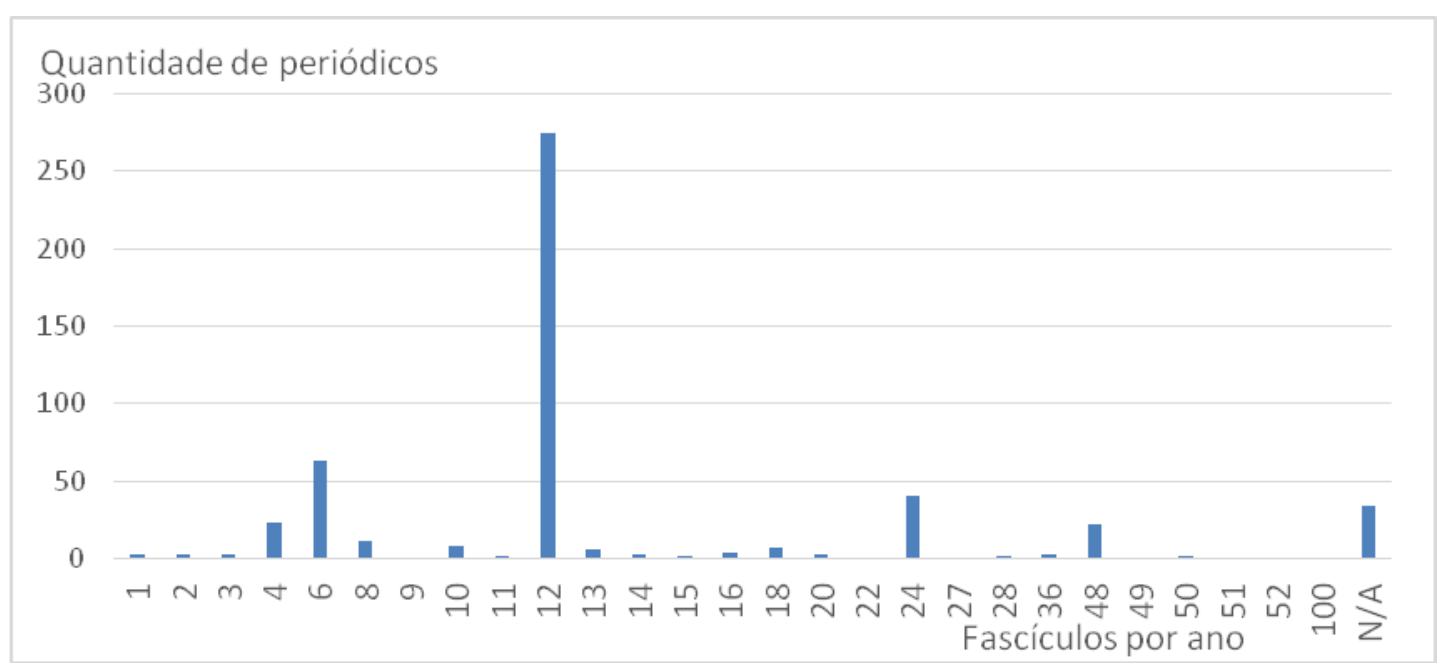

Fonte: Dados de pesquisa (2018).

Na coluna da Figura 5 está o número de periódicos contabilizados, enquanto na linha está o número de edições publicadas anualmente. Nota-se que a periodicidade mais observada foi a mensal (12 fascículos por ano), com 275 ocorrências. Em seguida estão a bimestral (6 fascículos por ano), com 63 ocorrências e a bimensal (24 fascículos por ano), com 41. Os 34 periódicos que publicavam de forma contínua, irregular ou desconhecida foram desconsiderados no cálculo da média e aparecem marcados no gráfico como N/A (não se aplica).

\subsubsection{Editoras dos periódicos A1 de medicina}

As editoras que pertenciam aos mesmos grupos comerciais foram agrupadas, com o objetivo de unificar a identificação das entidades editoras para fins de quantificação nesta pesquisa. A Figura 6, a seguir, ilustra a concentração editorial nos periódicos analisados: 
Figura 6 - Gráfico de concentração editorial

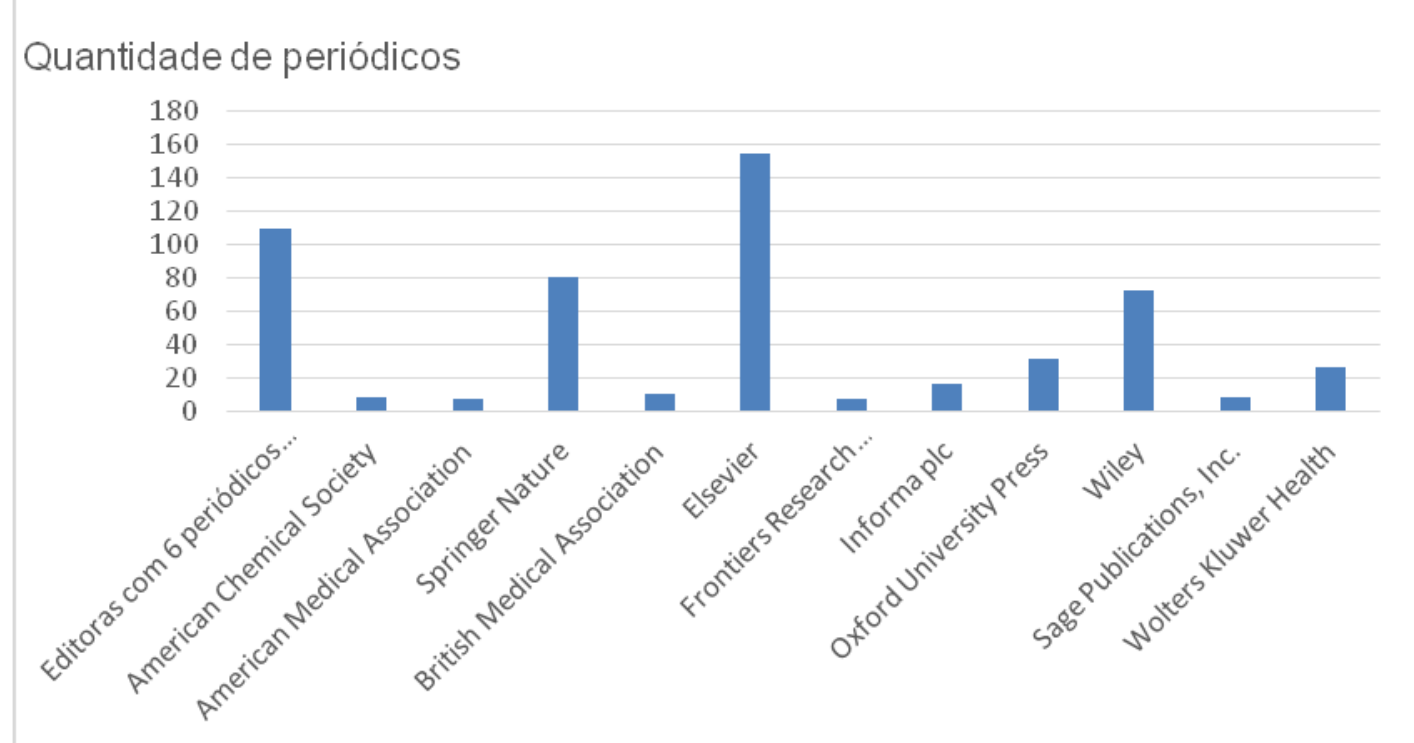

Fonte: Dados de pesquisa (2018).

Destaca-se na Figura 6 o número de periódicos pertencentes ao grupo editorial Elsevier (154), que supera, inclusive, a soma de todos os periódicos pertencentes a editoras com menor participação (109). Periódicos de editoras pertencentes ao grupo Elsevier correspondem a $29 \%$ do total analisado neste trabalho. Já a soma dos periódicos editorados por Wiley, Springer Nature e Elsevier chegam a 58\% do total.

Conforme os dados apresentados sobre a concentração editorial, mais da metade dos periódicos A1 das áreas de medicina do Qualis são editorados por 3 grandes grupos: Elsevier, Wiley e Springer Nature. Esses resultados corroboram o levantamento realizado por Larivière, Haustein e Mongeon (2015) no qual foi constatado que mais de $50 \%$ dos 45 milhões de documentos disponibilizados na WoS eram pertencentes a apenas cinco grandes editoras. De acordo com os autores, o mercado da publicação científica apresenta características de oligopólio, no qual grandes players possuem a privilegiada condição de determinar aumentos anuais nas taxas de assinatura, que por sua vez refletem na elevação de custos das pesquisas.

Além disso, as relações de vinculação entre algumas editoras não são muito claras, podendo-se citar o caso da Frontiers Research Foundation, que faz parte de uma empresa shareholder do grupo Springer Nature, porém operaria de forma independente, segundo declaração do próprio editor-chefe (ENSERINK, 2015). As definições para esse tipo de relação institucional requerem uma análise mais aprofundada. Assim, para casos como esse, optou-se por apresentar as editoras separadamente. 0 
gráfico da Figura 7 exibe o impacto por editora, com base no valor do fator unificado:

Figura 7 - Gráfico de fator unificado por editora

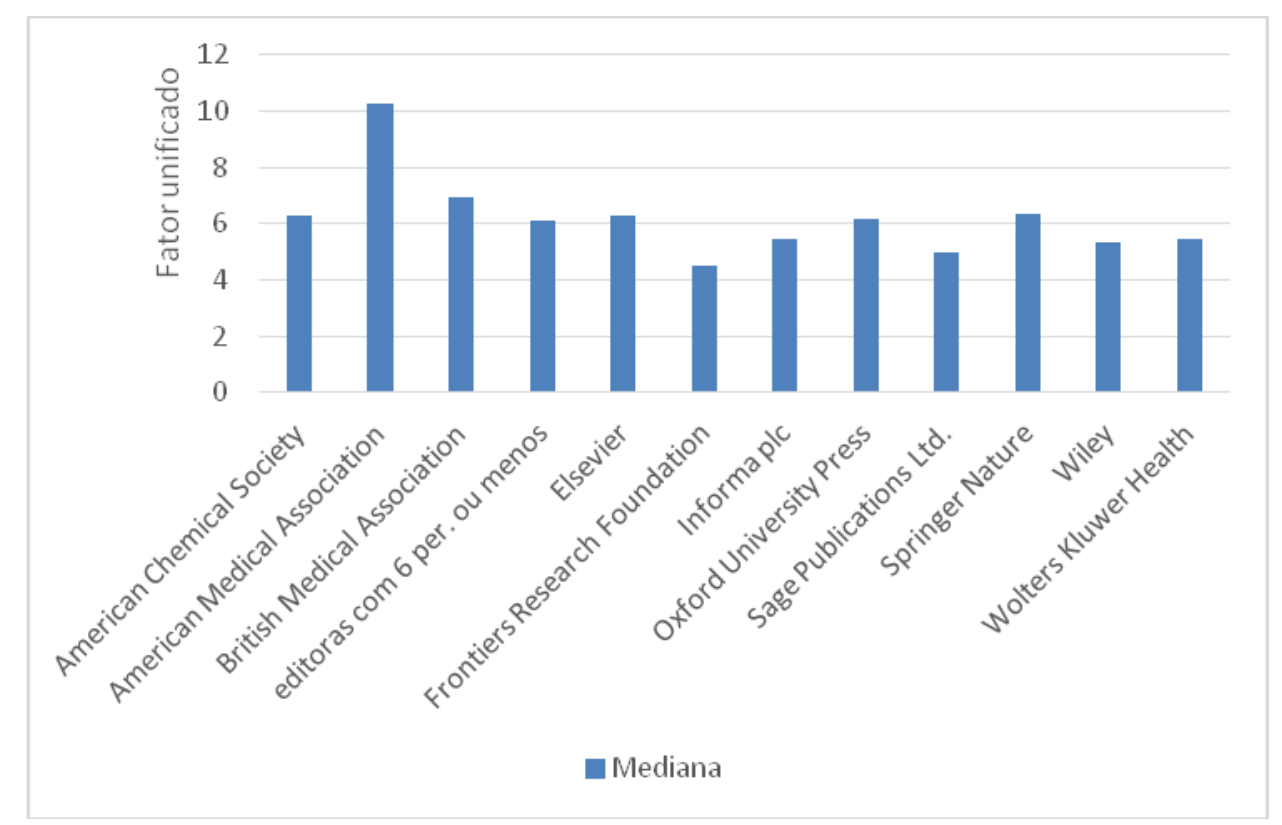

Fonte: Dados de pesquisa.

Pode-se observar pela Figura 7 que a editora com periódicos de maior impacto é a American Medical Association, com a mediana de 10,251 de fator unificado. A American Medical Association é uma associação científica e profissional de médicos e estudantes, fundada em 1847. Nas listas de medicinas A1 a editora é responsável por sete periódicos. O resultado da análise mostra a participação competitiva das associações científicas e profissionais no mercado dominado por editoras comerciais, porém novamente vale destacar que o resultado pode não representar bem a realidade dado o baixo número de periódicos nessa editora. As editoras comerciais detêm $78 \%$ do total de periódicos identificados neste estudo, as associações científicas são compostas por $14 \%$, e as universidades, $6 \%$. Institutos de pesquisa, organizações não governamentais, entre outros tipos de entidade somaram 6\%. A Figura 8, a seguir, retrata essa distribuição em detalhes: 
Figura 8 - Gráfico de entidades editoras

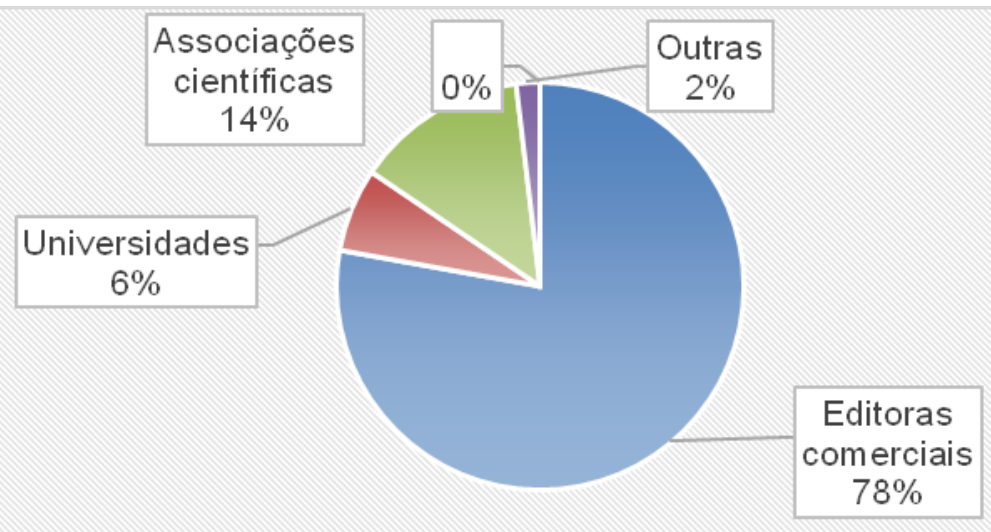

Fonte: Dados de pesquisa.

É possível observar pela Figura 8 que a grande maioria dos periódicos é gerida por entidades comerciais, o que mostra perfis diferentes dos observados na realidade dos periódicos brasileiros. Segundo Rodrigues e Abadal (2014), as universidades são responsáveis por $47 \%$ do total de periódicos editorados no Brasil, outros $40 \%$ são de associações científicas, e apenas $0.8 \%$ pertencente a editoras comerciais.

De acordo com Santos (2010), o sistema tradicional de comunicação científica orbita totalmente em torno das grandes editoras comerciais, que acabam por precificar seus produtos em níveis muito acima da inflação, captando o fruto do trabalho de terceiros e depois o vendendo aos próprios financiadores das pesquisas.

\subsubsection{Periódicos em Acesso Aberto A1 nas medicinas}

Os periódicos foram identificados como de Acesso Aberto quando apareciam indexados na base DOAJ. Dos 528 periódicos analisados, foram identificados 461 como acesso restrito ou híbridos, e 67 como sendo de Acesso Aberto, que correspondem a $13 \%$ do total. Destes, quatro foram identificados como sendo livres de APC, o que equivale a 5,97\% dos periódicos em Acesso Aberto e a $0,75 \%$ do total de periódicos analisados.

A taxa média dos periódicos que trabalham com APC é de 2.395,87 dólares americanos. O valor mínimo observado foi de 569,35 dólares para o periódico DNA Research, editorado pela Oxford University Press. Quanto ao valor máximo, foi de 5 mil dólares para o periódico Cell Reports, da editora Elsevier.

Os periódicos em Acesso Aberto apresentaram uma mediana de 5,372 no fator unificado, número muito próximo da mediana de 5,365 identificada naqueles com acesso restrito. Isso demonstra que não há 
diferenças significativas de impacto entre os modelos de acesso. A Figura 9 compara o fator unificado com as taxas de APC a fim de verificar se há relação entre os valores.

Figura 9 - Relação entre fator unificado e APC dos periódicos em Acesso Aberto

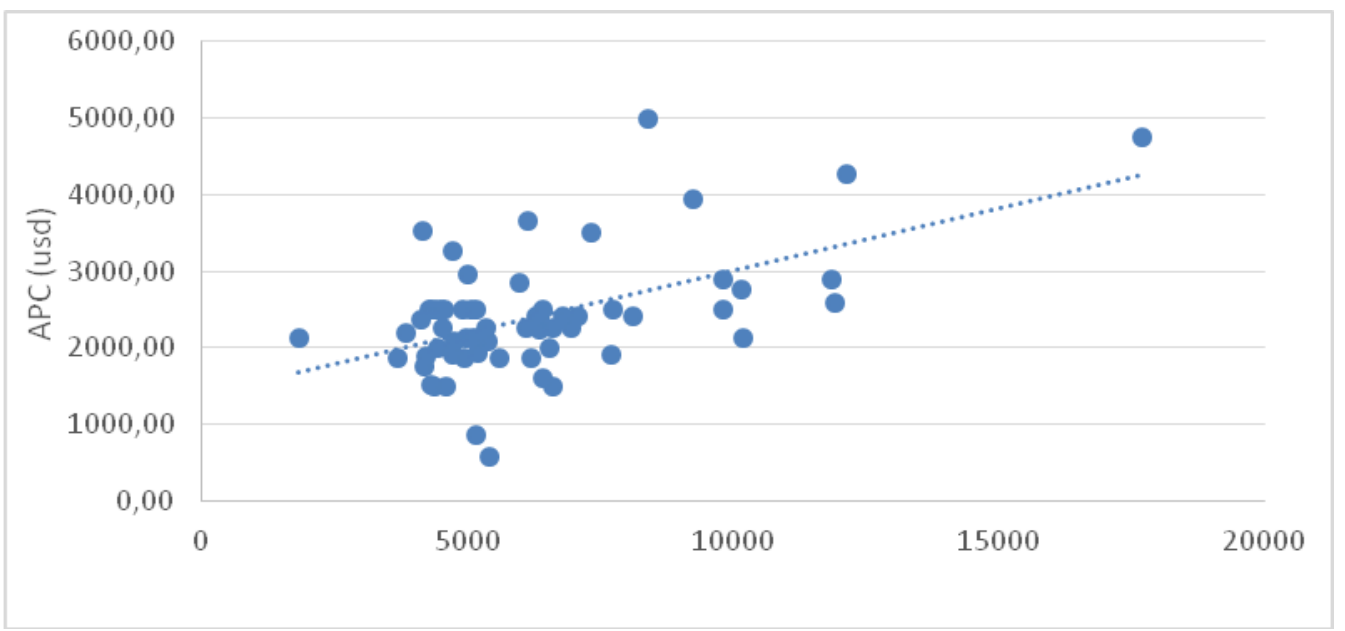

Fonte: Dados de pesquisa.

Uma linha de tendência de alta pode ser traçada a partir da dispersão dos resultados, o que indica uma correlação positiva entre as duas variáveis. Deste modo, o gráfico permite inferir que os valores de APC aumentam conforme aumenta o fator unificado dos periódicos. Esse resultado corrobora estudo anterior de Wang, Liu e Fang (2015), o qual concluiu que as APC são maiores em faixas maiores de FI.

Especificamente na área de ciências da saúde, Wang, Liu e Fang (2015) verificaram que a ausência de financiamento leva os autores dos manuscritos a optarem pela publicação em periódicos de subscrição em vez daqueles com cobrança de APC. Nos casos em que as APC são financiadas por universidades federais e agências de fomento, publicar em periódicos de elite também incorre em maior gasto de dinheiro público. Dinheiro que acaba sendo investido fora do país, tendo em vista que esses periódicos são em sua maioria geridos por grupos estrangeiros. Em momento de cortes orçamentários na educação, é crucial que a CAPES tenha consciência desses parâmetros, pois ao estimular a publicação em periódicos A1 por meio das avaliações do Qualis, acaba indiretamente estimulando maior aporte de recursos do próprio orçamento.

\subsubsection{Ano de criação dos periódicos de medicina}

Os periódicos analisados possuem em média 43 anos de existência e são compreendidos num período que varia entre 1665 - ano da criação do Philosophical Transactions pela Royal Society de Londres - até 2015. 
Apenas a Philosophical Transactions datava de antes do século XIX. Além dela, foram identificados 141 títulos que tiveram sua criação entre 2000 e 2015, outros 71 que foram criados entre 1900 e 1949, mais 288 entre 1950 e 1999, e 25 criados entre os anos de 1801 a 1899 . Quando o ano de criação exato não era fornecido pelo Ulrichs, os dados foram coletados nas páginas on-line dos periódicos, no entanto houve dois casos em que não foi possível fazer essa identificação.

Foi observada uma maior concentração de periódicos na faixa entre 1950 a 2015, período que sucedeu a Segunda Guerra Mundial, pelo que marcou a expansão da produção científica e ampliação do mercado editorial (MEADOWS, 1999). A quantidade de periódicos e a mediana do fator unificado por grupo são relacionadas pelo Quadro 2.

Quadro 2 - Anos de criação e fator unificado

\begin{tabular}{|c|c|c|}
\hline Período de criação & $\begin{array}{c}\text { Quantidade de } \\
\text { periódicos }\end{array}$ & Mediana fator unificado \\
\hline 1665 & 1 & 5,846 \\
\hline 1801 a 1899 & 25 & 6,347 \\
\hline 1900 a 1949 & 71 & 5,672 \\
\hline 1950 a 1999 & 288 & 6,429 \\
\hline 2000 a 2015 & 141 & \\
\hline
\end{tabular}

Fonte: Dados de pesquisa.

Conforme disposto pelo Quadro 2, o grupo observado com maior fator unificado foi o composto pelos periódicos criados entre 2000 a 2015, com a mediana de 6,429 , porém não afasta-se muito dos outros resultados.

\subsection{Perfil dos periódicos A1 em medicina}

O perfil dos periódicos $A 1$ nas áreas de medicina no Qualis foi estabelecido com base nas características editoriais apontadas na subseção 4.2. A representação do perfil foi construída a partir nos parâmetros apresentados no passo 8 da seção 3.2, sobre os procedimentos metodológicos. As médias foram adotadas para valores numéricos que não se afastavam muito da tendência central, apresentando baixo desvio padrão, como no cálculo das taxas de APC e periodicidade. Os quartis foram calculados quando houve um desvio padrão fora do normal entre os valores observados, como o caso do fator 
unificado. As modas foram adotadas na ocorrência de dados não numéricos, como a descrição da editora do periódico, país de origem e idioma do texto. Segundo Bussab e Morettin (2010, p.35), a "moda é definida como a realização mais frequente do conjunto de valores observados". Após os cálculos, as informações identificadas puderam servir de aporte para a definição das características comuns que um periódico A1 típico possui nessas áreas.

A mediana do fator unificado, observada por meio do cálculo de quartis, ficou em 5,365. Os países mais presentes nas listas foram Estados Unidos $(44,5 \%)$ e Reino Unido (38,25\%), sendo o idioma inglês praticamente unânime entre todos os resultados $(99,62 \%$ dos casos). A periodicidade mais observada foi a mensal (12 fascículos por ano). Quanto às entidades editoriais, a maioria é classificada como comercial (78\%), com destaque à editora holandesa Elsevier, que sozinha é responsável por $29 \%$ do total de periódicos analisados. Os anos de criação variam de 1665 a 2015, com a média de 43 anos de existência. Por fim, o Acesso Aberto não parece ser prioridade para os periódicos $A 1$ das áreas de medicina, constituindo um grupo com cerca de $13 \%$ do total.

Em suma, foi possível retratar um típico periódico $A 1$ das áreas de medicina com o seguinte perfil:

a) possui em torno 43 anos de existência;

b) é gerido por uma editora comercial;

c) possui fator unificado mediano de 5,365;

d) publica exclusivamente em inglês;

e) apresenta restrição de acesso em algum nível;

f) quando oferece Acesso Aberto, a taxa média de APC é de 2395,87 dólares;

g) publica com periodicidade mensal;

h) é proveniente dos Estados Unidos.

Os dados foram compatíveis com estudo similar de periódicos em outras áreas do Qualis que utilizam indicadores de citação para atribuição do estrato A1. Ao analisarem as características editoriais dos periódicos A1 na área de ciências biológicas, Neubert, Rodrigues e Müller (2017) verificaram que $83,96 \%$ eram mantidos por editoras comerciais com predominância da Elsevier; que o idioma inglês se fez presente em $99,98 \%$ dos casos; que as proveniências mais presentes foram de periódicos dos Estados Unidos (48,85\%) e Reino Unido (34,5\%); e que a adesão ao Acesso Aberto ocorria em 8,4\%. 
Quanto à ausência de periódicos brasileiros no estrato $A 1$, a mesma característica foi identificada em outras áreas que utilizam indicadores de citação como critérios exclusivos de avaliação, na área de administração (SAES; MELLO; SANDES-GUIMARÃES, 2017), na área de ciências agrárias (OLIVEIRA, 2015) e na área de ciências biológicas (NEUBERT; RODRIGUES; MÜLLER, 2017).

\section{Considerações finais}

Por meio da identificação dos periódicos Qualis A1 das medicinas o estudo apontou inconsistências na classificação realizada pela CAPES. Os problemas observados foram referentes à duplicidade de periódicos nas listas da Sucupira, erros no registro de ISSN, incompatibilidade dos critérios com as exigências para o estrato $A 1$, divergências na quantidade de periódicos informada nos documentos de área e uma possível confusão de periódicos com títulos similares.

Os dados dos títulos de medicina apresentados nessa pesquisa também apontaram um perfil com níveis de impacto acima de qualquer periódico do Brasil, texto publicado exclusivamente em inglês, acesso restrito e explícita dominância por parte das grandes editoras comerciais, como Elsevier e Wiley. Neste sentido, fica ilógica a competição entre periódicos brasileiros - em sua maioria de Acesso Aberto, sem fins comerciais - e os periódicos observados. As regras de proporcionalidade de estratos autoimpostas pela CAPES restringem a quantidade de periódicos $A 1$ que cada área pode apresentar, fazendo com que a tarefa de ascensão de um título brasileiro aos estratos mais altos torne-se árdua ou até inexequível.

O ranqueamento do Qualis aumenta a disparidade na ciência à medida que incentiva os pesquisadores brasileiros a submeterem seus manuscritos aos periódicos de estratos mais elevados, enquanto os títulos nas camadas mais baixas sofrem para atrair bons artigos e não conseguem se consolidar perante a comunidade científica. Segundo Silva e Mueller (2015, p.12) "Todos os critérios estabelecidos nos documentos de área contribuem, em maior ou menor grau para a acumulação de vantagens pelos mais bem situados e seus produtores".

Ainda que o Qualis consista num instrumento de avaliação da pósgraduação e seu uso seja contraindicado para outros fins (BARATA, 2016), a conquista de estratos mais elevados é almejada por periódicos científicos nacionais que buscam maior visibilidade. Sendo assim, os critérios utilizados acabam impactando no comportamento editorial de grande parcela desses títulos. Indo além, na busca por reconhecimento 
profissional e boa avaliação para seus programas de pós-graduação e instituições, os cientistas acabam submetendo seus trabalhos - e cedendo seus direitos patrimoniais - a periódicos de editoras comerciais com alto potencial de citação. No que Vilaça e Palma (2013) chamam de 'egofetichização da produção científica', pesquisadores são levados a produzirem e publicarem visando poder intelectual e financeiro entre seus pares. Este conceito apresenta-se como uma contraposição ao princípio do desinteresse proposto por Merton, e dá indicativos de que a produção científica, apesar de ser um processo colaborativo, pode expressar as pretensões individuais de seus agentes.

O fato de uma fundação vinculada ao Ministério da Educação brasileiro adotar políticas de avaliação baseadas em métricas que colocam em destaque periódicos estrangeiros de editoras comerciais, mostra-se contraproducente ao desenvolvimento dos veículos de comunicação científica nacionais. Tendo em vista que as áreas de medicina consideram apenas o Fator de Impacto do JCR ou Cites per Doc do Scimago na atribuição do Qualis A1, essa classificação tem o potencial de gerar um direcionamento em massa dos resultados das pesquisas científicas brasileiras para periódicos estrangeiros de acesso restrito. Esse sistema enfraquece os periódicos nacionais, os quais dificilmente conseguirão ascender aos estratos mais altos, ao passo que migra os estudos para periódicos de editoras comerciais estrangeiras e desabastece a comunidade científica global de material aberto. Além disso, gera o gasto duplicado, em que recursos públicos são destinados a subsidiar publicações comerciais com paywalls.

Para que os periódicos brasileiros não sejam relegados ao posto de ciência periférica não basta que a Capes apenas eleve artificialmente seus estratos. É preciso pensar em mecanismos alternativos de avaliação, da mesma forma que no desenvolvimento de uma política de fomento à publicação nos títulos de maior potencial, de forma que eles passem a ser referências em suas áreas.

\section{Referências}

ALLAHAR, H. Academic Publishing, Internet Technology, and Disruptive Innovation. Technology Innovation Management Review. Ontário, v. 7, n. 11, p. 47-56. 2017. Disponível em: http://www.timreview.ca/article/1120. Acesso em: 08 jan. 2018.

BARATA, R. B. Dez coisas que você deveria saber sobre o Qualis. Revista Brasileira de Pós-graduação, Brasília, v. 13, n. 30, p.13-40, 11 ago. 2016. Disponível em: 
http://ojs.rbpg.capes.gov.br/index.php/rbpg/article/view/947/pdf. Acesso em: 17 abr. 2018.

BARBOSA, A. S. Implicações éticas do efeito Mateus na ciência. Mediações - Revista de Ciências Sociais, Londrina, v. 21, n. 1, p.286-316, 19 ago. 2016. Disponível em: http://dx.doi.org/10.5433/21766665.2016v21n1p286. Acesso em: 24 jul. 2018 BONTIS, N.; SERENKO, A. A follow-up ranking of academic journals. Journal of Knowledge Management, Londres, v. 13, n. 1, p.16-26, 20 fev. 2009.

BUELA-CASAL, G. Evaluación de la calidad de los artículos y de las revistas científicas: propuesta del factor de impacto ponderado y de un índice de calidad. Psicothema, v. 15, n. 1, p. 23-35. Disponível em: http://www.psicothema.com/pdf/400.pdf. Acesso em 21 maio 2018.

BURANYI, $S$. Is the staggeringly profitable business of scientific publishing bad for science? The Guardian, 27 Jun. 2017. Disponível em: https://www.theguardian.com/science/2017/jun/27/profitable-businessscientific-publishing-bad-for-science. Acesso em: 13 jul. 2018.

BUSSAB, W. de O.; MORETTIN, P. A. Estatística básica. 6. ed. São Paulo: Saraiva, 2010. 540 p.

CALDERON, Iracema de Mattos Paranhos. Qualis evaluation of medicine III: analysis of anesthesiology and gynecology and obstetrics journals. Revista do Colégio Brasileiro de Cirurgiões, Rio de Janeiro, v. 42, n. 1, p.65-67, 2015. Disponível em:

http://www.scielo.br/scielo.php?pid=S010069912015000800065\&script=sci arttext\&tlng=pt. Acesso em: 10 set. 2018.

CAPES. Conselho Técnico-Científico da Educação Superior. 2018. Disponível em: http://www.capes.gov.br/conselho-tecnico-cientifico-daeducacao-superior. Acesso em: 19 abr. 2018.

CAPES. Diretoria de Avaliação - DAV. Considerações sobre o Qualis Periódicos (Med1). Brasília, 2016a. Disponível em:

http://www.capes.gov.br/images/documentos/Qualis periodicos 2016/Co nsideracoes Qualis Periodicos Area 152016 2013-2015.pdf. Acesso em: 16 nov. 2017.

CAPES. Diretoria de Avaliação - DAV. Considerações sobre o Qualis Periódicos (Med2). Brasília, 2016b. Disponível em: 
http://www.capes.gov.br/images/documentos/Qualis_periodicos 2016/Do cumento Qualis 2016 MEDICINA II.pdf. Acesso em: 16 nov. 2017.

CAPES. Diretoria de Avaliação - DAV. Critérios de Classificação Qualis Área Medicina III. Brasília, 2016c. Disponível em: http://www.capes.gov.br/images/documentos/Qualis periodicos 2016/Cri terios qualis med3.pdf. Acesso em: 16 nov. 2017.

CAPES. Diretoria de Avaliação - DAV. Documento de área: Medicina I. Brasília, 2016d. Disponível em: http://www.capes.gov.br/images/documentos/Documentos de area 201 7/15 MED I docarea 2016.pdf. Acesso em: 16 nov. 2017.

CAPES. Diretoria de Avaliação - DAV. Documento de área: Medicina II. Brasília, 2016e. Disponível em: http://www.capes.gov.br/images/documentos/Documentos de area 201 7/16 MED 2 docarea 2016.pdf. Acesso em: 16 nov. 2017.

CAPES. Diretoria de Avaliação - DAV. Documento de área: Medicina III. Brasília, 2016f. Disponível em:

http://www.capes.gov.br/images/documentos/Qualis periodicos 2016/Cri terios qualis med3.pdf. Acesso em: 28 ago. 2017.

COPE (Reino Unido). About COPE. 2018. Disponível em: https://publicationethics.org/about. Acesso em: 05 fev. 2018.

COSTA, A. L. F.; YAMAMOTO, O. H. Publicação e avaliação de periódicos científicos: paradoxos de avaliação qualis de psicologia. Psicologia em Estudo, Maringá, v.13, n.1, p 13-24, jan- mar. 2008. Disponível em: http://www.scielo.br/pdf/pe/v13n1/v13n1a02.pdf. Acesso em: 24 jun. 2017.

COSTA, R. O.; RAMOS, L. M. S. V. C. Periódicos brasileiros em Odontologia e a fuga dos artigos científicos de alto impacto. Atoz: novas práticas em informação e conhecimento, Curitiba, v. 3, n. 1, p.66-70, 1 set. 2014. Disponível em:

https://revistas.ufpr.br/atoz/article/view/41336. Acesso em: 08 out. 2018.

ENSERINK, M. Open-access publisher sacks 31 editors amid fierce row over independence. Science, 20 May 2015. Disponível em: http://www.sciencemag.org/news/2015/05/open-access-publisher-sacks31-editors-amid-fierce-row-over-independence. Acesso em: 08 jun. 2018.

FALAGAS, M. E. et al. Comparison of PubMed, Scopus, Web of Science, and Google Scholar: strengths and weaknesses. The Faseb Journal, 
Bethesda, v. 22, n. 2, p.338-342, fev. 2008. FASEB. Disponível em: https://www.fasebj.org/doi/pdf/10.1096/fj.07-9492LSF. Acesso em: 26 abr. 2018.

KELLNER, A. W. A. The Qualis system: a perspective from a multidisciplinary journal. An. Acad. Bras. Ciênc., Rio de Janeiro, v. 89, n. 3, p. 1339-1342, Set. 2017 . Disponível em: http://www.scielo.br/scielo.php?script=sci arttext\&pid=S000137652017000401339\&lng=en\&nrm=iso. Acesso em: 02 mar. 2018. KRZYZANOWSKI, R. F.; FERREIRA, M. C. G. Avaliação de periódicos científicos e técnicos brasileiros. Ciência da Informação, Brasília, v. 27, n. 2, p.165-175, out. 1998. Disponível em: http://revista.ibict.br/ciinf/article/view/798/829. Acesso em: 11 jul. 2018.

LARIVIÈRE, V.; HAUSTEIN, S.; MONGEON, P. The oligopoly of academis publishers in the digital era. PLOS One, v. 10, n.6, 2015. Disponível em: http://www.plosone.org/article/fetchObject.action?uri=info:doi/10.1371/j ournal.pone.0127502\&representation=PDF. Acesso em: 20 out. 2017.

LEE, K. P. et al. Association of Journal Quality Indicators With Methodological Quality of Clinical Research Articles. JAMA, v. 287, n. 21, p.2805-2816, 5 jun. 2002. Disponível em: http://dx.doi.org/10.1001/jama.287.21.2805. Acesso em: 12 jul. 2018. LEITE, F.B.; CODATO, A. Autonomização e institucionalização da Ciência Política brasileira: o papel do sistema Qualis-Capes. Agenda Política, v. 1, p. 1-21, 2013.

MACFARLANE, B.; MING CHENG. Communism, Universalism and Disinterestedness: Re-examining Contemporary Support among Academics for Merton's Scientific Norms. Journal of Academic Ethics, v. 6: 67-78, 2008. Disponível em:

http://web.edu.hku.hk/f/acadstaff/367/Communism Universalism and Di sinterestedness.pdf. Acesso em: 17 out. 2017.

MANZINI, E. J. Avaliação de periódicos científicos: Revista Brasileira de Educação Especial. Revista Brasileira de Educação Especial, Brasília, v. 19, n. 1, p.121-130, mar. 2013. Disponível em: http://dx.doi.org/10.1590/s1413-65382013000100009. Acesso em: 17 jul. 2018.

MARCHLEWSKI, C., SILVA, P. M., \& SORIANO, J. B. A influência do sistema de avaliação Qualis na produção de conhecimento científico: 
Algumas reflexões sobre a Educação Física. Motriz: Revista de Educação Fisica, v. 17, n.1, 104-116. 2011. Disponível em: http://www.scielo.br/pdf/motriz/v17n1/a12v17n1.pdf. Acesso em 17 abr. 2018.

MEADOWS, A. J. A comunicação científica. Brasília: Briquet de Lemos/Livros, 1999.

MERTON, R. K. The Matthew Effect in Science: The reward and communication systems of science are considered. Science, v. 159, n. 3810, p.56-63, 5 jan. 1968. American Association for the Advancement of Science (AAAS). Disponível em: http://science.sciencemag.org/content/159/3810/56. Acesso em: 23 jul. 2018.

MUELLER, S. P. M. A comunicação científica e o movimento de acesso livre ao conhecimento. Ciência da Informação, Brasília, v. 35, n. 2, p. 27-38, 2006. Disponível em: http://revista.ibict.br/ciinf/article/view/1138/1293. Acesso em 21 maio 2018.

MUELLER, S. P. M. O círculo vicioso que prende os periódicos nacionais. DataGramaZero: Revista de Ciência da Informação, v. 1, n. zero, p.1-8, dez. 1999. Disponível em: http://eprints.rclis.org/11196/1/Artigo 04.pdf. Acesso em: 27 jul. 2018.

MUGNAINI, R. Ciclo avaliativo de periódicos no Brasil: caminho virtuoso ou colcha de retalhos?. In: ENANCIB, 16., 2015, João Pessoa. Produção e Comunicação da Informação em Ciência, Tecnologia \& Inovação. João Pessoa: Benancib, 2017. p. 1 - 19. Disponível em:

http://200.20.0.78/repositorios/handle/123456789/2947. Acesso em: 12 jul. 2018.

MUGNAINI, R.; POBLACIÓN, Dinah A. de Melo Aguiar. Multidisciplinaridade e especificidade na comunicação científica: discussão do impacto na avaliação de diferentes áreas. Reciis: Revista Eletrônica de Comunicação, Informação \& Inovação Em Saúde, v. 4, p. 3, 2010. Disponível em: https://www. reciis. icict.fiocruz.br/index.php/reciis/article/view/533/1176. Acesso em 17 abr. 2018.

NEUBERT, P.; RODRIGUES, R. S.; MÜLLER, Y. M. Periódicos científicos de ciências biológicas: estudo dos títulos classificados no estrato A1 do Qualis. Reciis: Revista eletrônica de comunicação, informação e inovação em saúde, Rio de Janeiro, v. 11, n. 3, p.1-15, jul. 2017. Disponível em: https://www. reciis. icict.fiocruz.br/index.php/reciis/article/view/1251. Acesso em: 10 out. 2018. 
OliVeIRA, A. B. Periódicos científicos das Ciências Agrárias: análise dos títulos brasileiros indexados na Web of Science e Scopus. 2015. 278 p. Dissertação (Mestrado em Ciência da Informação) - Programa de PósGraduação em Ciência da Informação, Universidade Federal de Santa Catarina, Florianópolis, 2015.

PACKER, A. L.; MENEGHINI R. A vez dos periódicos de qualidade do Brasil. SciELO em Perspectiva, 2017. Disponível em:

http://blog.scielo.org/blog/2017/11/08/a-vez-dos-periodicos-dequalidade-do-brasil/. Acesso em: 05 fev. 2018.

PACKER, A. L. A eclosão dos periódicos do Brasil e cenários para o seu porvir. Educ. Pesqui., São Paulo, v. 40, n. 2, p. 301-323, 2014. Disponível em: http://www.scielo.br/scielo.php?script=sci arttext\&pid=S151797022014000200002\&lng=en\&nrm=iso. Acesso em: 24 jun. 2018.

RODACKI, A. L. F. Qualis: Implicações para a avaliação de programas de pós-graduação das diferentes áreas do conhecimento - uma análise preliminar. Revista Brasileira de Pós-graduação, Brasília, v. 13, n. 30, p.65-76, 11 ago. 2016. Disponível em: http://dx.doi.org/10.21713/23582332.2016.v13.1129. Acesso em: 17 abr. 2018.

RODRIGUES, R. S.; ABADAL, E. Scientific journals in Brazil and Spain: alternative publisher models. Journal of The American Society For Information Science and Technology, v. 65, n. 2, p. 1-7, fev. 2014. Disponível em: http://dx.doi.org/10.1002/asi.23115. Acesso em: 08 jun. 2018.

SANTOS, S. M. Perfil dos periódicos científicos de ciências sociais e de humanidades: mapeamento das características extrínsecas. $176 \mathrm{f}$. Dissertação (Mestrado em Ciência da Informação) - Escola de Comunicações e Artes, Universidade de São Paulo, São Paulo, 2010. 176p. SILVA, C. N. N.; MUELLER, S. P. M. Avaliação dos periódicos brasileiros: os critérios do qualis-periódico à luz de Merton e Bourdieu. Encontro Nacional de Pesquisa em Ciência da Informação, v. 16, 2015. Disponível em: http://www.brapci.inf.br/index.php/article/download/43946. Acesso em: 10 jul. 2017.

SAES, M.; MELLO, A.; SANDES-GUIMARÃES, L. V. Revistas brasileiras em administração: relevância para quem? Revista de Administração de Empresas, São Paulo, v. 57, n. 5, p.515-519, set. 2017. Disponível em: http://dx.doi.org/10.1590/s0034-759020170509. Acesso em: 08 out. 2018. 
SOMA, N. Y.; ALVES, A. D.; YANASSE, H. H. O Qualis Periódicos e sua utilização nas avaliações. Revista Brasileira de Pós-graduação, Brasília, v. 13, n. 30, p.47-61, 11 ago. 2016. Disponível em:

http://ojs.rbpg.capes.gov.br/index.php/rbpg/article/view/1128/pdf. Acesso em: 17 abr. 2018.

STUMPF, I. R. C. Avaliação das revistas de Comunicação pela comunidade acadêmica da área. Em Questão, Porto Alegre, v. 9, n. 1, p. 25-38, jan./jun. 2003. Disponível em:

http://seer.ufrgs.br/index.php/EmQuestao/article/view/57/17. Acesso em: 12 jul. 2018.

TENNANT, J. Elsevier are corrupting open science in Europe. 2018.

Disponível em: https://www.theguardian.com/science/politicalscience/2018/jun/29/elsevier-are-corrupting-open-science-in-europe. Acesso em: 03 jul. 2018.

TENOPIR, C.; KING, D. W. Reading behaviour and electronic journals. Learned Publishing, Hoboken, v. 15, n. 4, p.259-265, out. 2002.

Disponível em: https://onlinelibrary.wiley.com/doi/pdf/10.1087/095315102760319215. Acesso em: 27 jul. 2018.

THE AUTHOREA TEAM (Estados Unidos da América). 65 out of the 100 most cited papers are paywalled. 2016. Disponível em: https://www.authorea.com/users/8850/articles/125400-65-out-of-the100-most-cited-papers-are-paywalled/ show article\#. Acesso em: 10 nov. 2017.

TRZESNIAK, Piotr. As dimensões da qualidade dos periódicos científicos e sua presença em um instrumento da área de educação. Revista Brasileira de Educação, v. 11, n. 32, maio/ago. 2006. Disponível em: http://www.scielo.br/scielo.php?script=sci arttext\&pid=S141324782006000200013\&lng=pt\&tlng=pt. Acesso em: 10 jul. 2018.

VASEN, F. ; VILCHIS, I.L. Sistemas nacionales de clasificación de revistas científicas en América Latina: tendencias recientes e implicaciones para la evaluación académica en ciencias sociales. Revista Mexicana de Ciencias Políticas y Sociales, Cidade do México, v. 62, n. 231, p.199-228, dez. 2017. Disponível em: http://www.revistas.unam.mx/index.php/rmcpys/article/view/58652. Acesso em: 18 abr. 2017. 
VILAÇA, M. M.; PALMA, A. Diálogo sobre cientometria, mal-estar na academia e a polêmica do produtivismo. Revista Brasileira de Educação (Impresso), v. 18, p. 467-484, 2013.

WANG, L. L.; LIU, X. Z.; FANG, H. Investigation of the degree to which articles supported by research grants are published in open access health and life sciences journals. Scientometrics, v. 104, n. 2, p.511-528, 20 jun. 2015. Disponível em: http://dx.doi.org/10.1007/s11192-015-1624-4. Acesso em: 10 out. 2018.

YAMAMOTO, O. J. et al. Avaliação de periódicos científicos brasileiros da área da psicologia. Ciência da Informação, Brasília, v. 31, n. 2, p.166-177, maio 2002. Disponível em:

https://www.lume.ufrgs.br/handle/10183/91015. Acesso em: 30 jul. 2018. 